\title{
Epitaxial $\mathrm{NbC}_{x} \mathrm{~N}_{1-x}(001)$ layers: growth, mechanical properties, and electrical resistivity
}

\author{
K. Zhang, ${ }^{\mathrm{a}, \mathrm{b}}$ K. Balasubramanian, ${ }^{\mathrm{a}}$ B.D. Ozsdolay, ${ }^{\mathrm{a}}$ C.P. Mulligan, ${ }^{\mathrm{a}, \mathrm{c}}$ S.V. Khare, ${ }^{\mathrm{d}}$
} W.T. Zheng, ${ }^{\mathrm{b}}$ and D. Gall ${ }^{\mathrm{a},{ }^{*}}$

\begin{abstract}
${ }^{a}$ Department of Materials Science and Engineering, Rensselaer Polytechnic Institute, Troy, NY 12180, USA. ${ }^{b}$ Department of Materials Science, Key Laboratory of Mobile Materials, MOE, and State Key Laboratory of Superhard Materials, Jilin University, Changchun 130012, People's Republic of China.

${ }^{c}$ U.S. Army Armament Research Development \& Engineering Center, Benét Laboratories, Watervliet, NY 12189, USA

${ }^{d}$ Department of Physics and Astronomy, University of Toledo, 2801 West Bancroft Street, Toledo, OH 43606, USA
\end{abstract}

$\mathrm{NbC}_{x} \mathrm{~N}_{1-x}$ layers were deposited on $\mathrm{MgO}(001)$ by reactive magnetron co-sputtering from $\mathrm{Nb}$ and graphite targets in $5 \mathrm{mTorr}$ pure $\mathrm{N}_{2}$ at $T_{s}=600-1000{ }^{\circ} \mathrm{C}$. The anion-to- $\mathrm{Nb}$ ratio of $1.09 \pm 0.05$ is independent of $T_{s}$ and indicates a nearly stoichiometric rock-salt structure $\mathrm{Nb}(\mathrm{N}, \mathrm{C})$ solid solution. In contrast, the C-to-N ratio increases from $0.20-0.59$ for $T_{s}=600-1000{ }^{\circ} \mathrm{C}$, which is attributed to a low $\mathrm{C}$ sticking probability at high $\mathrm{N}$ surface coverage at low $T_{s}$. Layers grown at $T_{s} \geq 700{ }^{\circ} \mathrm{C}$ are epitaxial single-crystals with a cube-on-cube relationship to the substrate, $(001)_{\mathrm{NbCN}} \|(001)_{\mathrm{MgO}}$ and $[100]_{\mathrm{NbCN}} \|[100]_{\mathrm{MgO}}$, as determined from X-ray diffraction $\theta-2 \theta$ and $\phi$ scans. Reciprocal space mapping on a $\mathrm{NbC}_{0.37} \mathrm{~N}_{0.63}$ layer deposited at $T_{s}=1000{ }^{\circ} \mathrm{C}$ indicates an in-plane compressive strain of $-0.4 \%$ and a relaxed lattice constant of $4.409 \pm 0.009 \AA$. The lattice constant of $\mathrm{NbC}_{x} \mathrm{~N}_{1-x}$ increases with $x$, consistent with a linear increase predicted by firstprinciples density functional calculations. The calculated bulk modulus, $307 \mathrm{GPa}$ for $\mathrm{NbN}$ and $300 \mathrm{GPa}$ for $\mathrm{NbC}$, is nearly independent of $x$. Similarly, $c_{11}$ increases slightly from 641 to 666 GPa, but $c_{12}$ decreases considerably from 140 to $117 \mathrm{GPa}$, and $c_{44}$ more than doubles from 78 to $171 \mathrm{GPa}$ as $x$ increases from 0 to 1 , indicating a transition from ductile $\mathrm{NbN}$ to brittle $\mathrm{NbC}$. This also results in an increase in the predicted isotropic elastic modulus from 335 to $504 \mathrm{GPa}$, which is in good agreement with the measured $350 \pm 12$ GPa for $\mathrm{NbC}_{x} \mathrm{~N}_{1-x}(001)$ with $x=0.19-0.31$. The hardness $H=22 \pm 2 \mathrm{GPa}$ of epitaxial $\mathrm{NbC}_{x} \mathrm{~N}_{1-x}$ layers is nearly independent of $x=0.19-0.37$ and $T_{s}=700-1000{ }^{\circ} \mathrm{C}$, but is reduced to $H=18.2 \pm 0.8 \mathrm{GPa}$ for the nanocrystalline layer deposited at $T_{s}=600{ }^{\circ} \mathrm{C}$. The electrical resistivity decreases strongly with increasing $T_{s}<800{ }^{\circ} \mathrm{C}$, due to increasing crystalline quality, and is $262 \pm 21 \mu \Omega$-cm at room temperature and $299 \pm 22 \mu \Omega$-cm at $77 \mathrm{~K}$ for $T_{s} \geq 800{ }^{\circ} \mathrm{C}$, indicating weak carrier localization due to the random distribution of $\mathrm{C}$ atoms on anion sites.

Keywords: Niobium Nitride; Niobium Carbide; Elastic constants; Mechanical properties; Resistivity; Hardness *corresponding author: ph:+1-518-276-8471, fax: +1-518-276-8554, gall@ rpi.edu 


\section{INTRODUCTION}

Transition-metal nitrides and carbides are well known for their remarkable physical properties including high hardness, excellent thermal stability, chemical inertness, corrosion resistance and electrical resistivities that vary from metallic to semiconducting [1-6]. Among the transition metal nitrides and carbides, both $\mathrm{NbN}$ and $\mathrm{NbC}$ have attracted considerable attention and are evaluated for potential industrial applications. They have gained interest due to their relatively high superconducting transition temperatures of $T_{\mathrm{c}}=17.3 \mathrm{~K}$ [7] and $12 \mathrm{~K}$ [8], respectively, with potential applications in superconducting electronics $[9,10]$. They are also promising as protective coating materials due to their high chemical stability [11], high melting points of 2204 [12] and $3600{ }^{\circ} \mathrm{C}$ [13], respectively, and high hardness with reported values that range from 7-48.5 GPa for $\mathrm{NbN}$ [14-19] and from 11.3-36.8 GPa for $\mathrm{NbC}[20,21]$. Both $\mathrm{NbN}$ and $\mathrm{NbC}$ exhibit metallic conductivity with reported room temperature resistivities $\rho_{\mathrm{NbN}}=88$ $750 \mu \Omega-\mathrm{cm}[19,22,23]$ and $\rho_{\mathrm{NbC}}=250-1200 \mu \Omega-\mathrm{cm} \mathrm{[24].}$

Ternary transition-metal carbonitride coatings have gained increased interest in recent years, because their mechanical and tribological properties can outperform those of the binary nitride and carbide coatings [25-32]. For example, the solid solution $\operatorname{TiC}_{x} \mathrm{~N}_{y}$ compound deposited by cathodic arc ion plating exhibits a lower friction and wear and a higher hardness than TiN, and is therefore promising for tribological applications [25]. Similarly, $\operatorname{CrC}_{x} \mathrm{~N}_{y}$ coatings produced by evaporation in a thermionic-arc ion-plating apparatus at $450{ }^{\circ} \mathrm{C}$ show a higher corrosion resistance than $\mathrm{CrN}$ coatings [26], and $\mathrm{MoC}_{x} \mathrm{~N}_{y}$ films deposited by reactive directcurrent magnetron sputtering have a higher hardness than both MoC and MoN films [32]. While both binaries $\mathrm{NbN}$ and $\mathrm{NbC}$ are well-studied, relatively little is known regarding the deposition and particularly the mechanical properties of ternary $\mathrm{NbC}_{x} \mathrm{~N}_{y}$ coatings. The few reports on 
Niobium carbonitride focus on its superconductive properties, with measured transition temperatures ranging from 13.2-17.8 $\mathrm{K}$ for layers that exhibit primarily a B1 crystal structure and are deposited by magnetron and ion-beam sputtering [33-36]. In a first effort to determine mechanical and tribological properties of $\mathrm{NbC}_{x} \mathrm{~N}_{y}$, we have recently deposited polycrystalline $\mathrm{NbC}_{x} \mathrm{~N}_{y}$ films by magnetron sputtering and reported a maximum hardness $H=42.1 \mathrm{GPa}$ for a $\mathrm{NbC}_{1.44} \mathrm{~N}_{0.44}$ film which contains both solid solution $\mathrm{Nb}(\mathrm{C}, \mathrm{N})$ grains and amorphous $\mathrm{C}(\mathrm{N})$, and found that inclusion of an increasing $\mathrm{sp}^{2}$-graphite-like carbon phase reduces friction and wear but ultimately causes a reduction in the mechanical strength [37]. The measured mechanical properties are strongly affected by the microstructure, including grain size, residual stress, and especially inclusions of secondary phases like amorphous $\mathrm{C}$ and hexagonal $\mathrm{NbN}$ [37]. Therefore, in order to determine the intrinsic mechanical properties of B1-structure solid solution $\mathrm{Nb}(\mathrm{C}, \mathrm{N})$, which is the primary phase that constitutes $\mathrm{NbC}_{x} \mathrm{~N}_{y}$, it is key to synthesize phase-pure singlecrystal layers. In addition, a stoichiometric anion-to-cation ratio of unity is required to minimize point defects including vacancies and interstitials. That is, $y=1-x$ and the layer can be labeled as $\mathrm{NbC}_{x} \mathrm{~N}_{1-x}$. This approach of using stoichiometric epitaxial single-crystal layers to determine the mechanical properties has already been applied to a range of transition metal nitrides including $\operatorname{TiN}(001)$ [38], $\mathrm{ScN}(001)$ [39], $\mathrm{TaN}(001)$ [40-42], $\mathrm{HfN}(001)$ [43, 44], $\mathrm{NbN}(001)$ [19], $\mathrm{CrN}(001)$ [45], and $\mathrm{CeN}(001)$ [46].

In this paper, we present the results of an investigation on the growth and physical properties of epitaxial $\mathrm{NbC}_{x} \mathrm{~N}_{1-x}$ layers deposited by reactive magnetron co-sputtering in $5 \mathrm{mTorr}$ pure $\mathrm{N}_{2}$ on $\mathrm{MgO}(001)$ at different substrate temperatures $T_{s}=600-1000{ }^{\circ} \mathrm{C}$. A combination of energy dispersive spectroscopy (EDS) and x-ray diffraction (XRD) show that the $\mathrm{NbC}_{x} \mathrm{~N}_{1-x}$ layers grown at $T_{s}=700-1000{ }^{\circ} \mathrm{C}$ are epitaxial single crystals with a stoichiometric anion-to- 
cation ratio and $x=0.19-0.37$ that increases with $T_{s}$ and causes an increase in the out-plane lattice constant with increasing $x$. The hardness of the epitaxial layers measured by nanoindentation is nearly unaffected by $T_{s}=700-1000{ }^{\circ} \mathrm{C}$, but is considerably lower for $T_{s}=$ $600{ }^{\circ} \mathrm{C}$ because of the nanocrystalline microstructure, which also causes a considerably higher electrical resistivity than for the epitaxial layers. The resistivity at $77 \mathrm{~K}$ is higher than at room temperature for all layers, indicating that carrier localization effects dominate electron transport. First-principles calculations are used to predict the lattice constant and elastic constants of $\mathrm{NbC}_{x} \mathrm{~N}_{1-x}$ as a function of $x$. There is overall good agreement between the predicted and measured values. In addition, the calculations indicate that the higher elastic modulus of $\mathrm{NbC}_{x} \mathrm{~N}_{1-x}$ in comparison to $\mathrm{NbN}$ is primarily due to an increase in the shear modulus with increasing $x$, which is associated with an increasing bond directionality that also causes a ductileto-brittle transition.

\section{EXPERIMENTAL AND COMPUTATIONAL PROCEDURE}

The $\mathrm{NbC}_{x} \mathrm{~N}_{1-x}$ films were deposited in a load-locked multichamber ultrahigh vacuum DC dual magnetron sputter deposition system with a base pressure of $10^{-9}$ Torr $\left(1.3 \times 10^{-7} \mathrm{~Pa}\right)$ [47], onto one-side polished $10 \times 10 \times 0.5 \mathrm{~mm}^{3} \mathrm{MgO}(001)$ wafers that were ultrasonically cleaned in subsequent baths of trichloroethylene, acetone and isopropyl alcohol, rinsed in de-ionized water, blown dry with dry nitrogen, mounted onto a substrate holder using silver paint, inserted into the deposition system, and degassed for 1 hour at $1000{ }^{\circ} \mathrm{C}$ using a radiative pyrolytic graphite heater [48]. The heater current was adjusted to reach the desired substrate temperature $T_{s}=600,700$, 800,900 and $1000{ }^{\circ} \mathrm{C}$, as measured with a pyrometer that was cross-calibrated by a thermo 
couple underneath the substrate holder. $99.999 \%$ pure $\mathrm{N}_{2}$ was further purified with a MicroTorr purifier and introduced into the chamber with a needle valve to reach a constant pressure of 5 mTorr $(=0.67 \pm 0.02 \mathrm{~Pa})$, measured with a capacitance manometer. Pure $\mathrm{N}_{2}$ processing gas was chosen over the more conventional $\mathrm{Ar}+\mathrm{N}_{2}$ mixture because (i) the higher nitrogen partial pressure in pure $\mathrm{N}_{2}$ provides a larger flux of nitrogen onto the growth surface and, (ii) pure $\mathrm{N}_{2}$ is commonly used for the epitaxial growth of transition metal nitrides including $\operatorname{TiN}(001)[49,50]$, $\mathrm{CrN}(001)$ [51-53], $\mathrm{ScN}(001)$ [54], and $\mathrm{Sc}_{1-x} \mathrm{Al}_{x} \mathrm{~N}(001)$ [55]. Water-cooled 5-cm-diameter $\mathrm{Nb}$ and C targets with purities of $99.95 \%$ and $99.999 \%$, respectively, were positioned both at $9.3 \mathrm{~cm}$ from the substrate at an angle of $45^{\circ}$ with respect to the substrate surface normal. The substrate was continuously rotated at $60 \mathrm{~min}^{-1}$ to increase thickness uniformity. Sputtering was carried out at a constant power of 300 and $100 \mathrm{~W}$ to the $\mathrm{Nb}$ and $\mathrm{C}$ targets, yielding deposition rates of 12 and $5 \mathrm{~nm} / \mathrm{min}$ for binary nitrides, as determined using thickness measurements from scanning electron micrographs of cross-sectional specimens. The power to the $\mathrm{C}$ target was chosen to obtain coatings containing approximately 10-20 at.\% $\mathrm{C}$, as discussed in more detail in the Results section. The deposition time is adjusted to achieve a thickness for all ternary coatings in this report of $2.2 \pm 0.1 \mu \mathrm{m}$.

The film composition was determined by energy dispersive spectroscopy (EDS) using a FEI Helios Nanolab scanning electron microscope operated with a 0.69-1.4 nA 5.0 keV primary beam and a working distance of $5.0 \mathrm{~mm}$. An Oxford Instruments X-Max 80 silicon drift detector which is particularly well suited for light element analysis is used to acquire EDS spectra. This system has been calibrated using the single beam current Oxford Instruments QCAL approach which takes into account width, position, and shape of each peak profile, and 
has been tested with $\mathrm{BN}$ and $\mathrm{CaSiO}_{3}$ standards (Micro-Analysis Consultants Ltd.), indicating a quantitative accuracy with $<3 \%$ error even for light elements including $\mathrm{B}, \mathrm{N}$, and $\mathrm{O}$.

X-ray diffraction (XRD) was done using a Panalytical X'pert PRO MPD system with a $\mathrm{Cu}$ source and a PIXcel line detector. A divergent beam configuration was used for $\theta-2 \theta$ scans. In-plane layer orientation was determined from $\phi$-scans with $\omega$ and $2 \theta$ angles set to detect the 113 peaks, using an $\omega$-offset of $25.24^{\circ}$, a parallel-beam configuration with an $\mathrm{x}$-ray mirror, and a detector receiving angle of $0.27^{\circ}$. Reciprocal space maps around asymmetric 113 reflections were obtained using a hybrid mirror two-bounce monochromator that provides $\mathrm{Cu} \mathrm{K} \alpha_{1}$ radiation with a $0.0068^{\circ}$ divergence, and a small $\sim 10^{\circ}$ angle between the sample surface and the reflected beam to reduce the beam width which facilitates fast and high-resolution parallel detection over 256 channels in $2 \theta$ with the line detector.

Nanoindentation measurements were done using a Hysitron Triboindenter with a maximum load of $10 \mathrm{mN}$. The area function of the triangular Berkovich diamond tip was calibrated using fused silica, following the procedure described in Ref. [56]. For each sample, nine indent sequences were applied. Outlier data points which are attributed to surface contamination effects were excluded from the subsequent analysis such that the hardness and elastic modulus for each sample were determined by averaging over 7-9 indent sequences. The indentation depth ranged for all samples from $90-107 \mathrm{~nm}$, which corresponds to only $4-5 \%$ of the $2.2 \pm 0.1 \mu \mathrm{m}$ film thickness, such that substrate effects can be neglected during the nanoindentation analyses. The resistivity of the coatings was measured using a spring loaded linear four point probe with the sample in air at room temperature $(295 \mathrm{~K})$ or immersed in liquid $\mathrm{N}_{2}$ at $77 \mathrm{~K}$, using a Keithley current source operating at -4.0 to $+4.0 \mathrm{~mA}$. 
First-principles density functional calculations were performed using the Vienna ab initio simulation package (VASP), employing periodic boundary conditions, a plane wave basis set, the Perdew-Burke-Ernzerhof generalized gradient approximation (GGA) exchange correlation functional [57], and the projector-augmented wave method [58] . An energy convergence of $<1$ meV/atom was achieved with a $500 \mathrm{eV}$ energy cut-off for the plane wave expansion and a $\Gamma$ centered $20 \times 20 \times 20 \mathrm{k}$-point grid for 8 -atom unit cells. $\mathrm{Nb} 4 s, 4 p$, and $4 d$ electrons are explicitly calculated, that is, they are not included in the core of the $\mathrm{Nb}$ pseudo potential. Enthalpies of formation of rocksalt-structure $\mathrm{NbN}$ and $\mathrm{NbC}$ from bcc $\mathrm{Nb}$, graphite, and molecular $\mathrm{N}_{2}$ were found to be -2.0 and $-1.1 \mathrm{eV}$ per formula unit, respectively, where the negative sign indicates that the nitride and carbide are more stable than the phase-separated elements. Rocksalt structure solid-solution $\mathrm{NbC}_{x} \mathrm{~N}_{1-x}$ was simulated with a conventional cubic cell where the four cation sites are filled with $\mathrm{Nb}$ atoms and each anion site is occupied either by a $\mathrm{N}$ or $\mathrm{C}$ atom, depending on the composition. The lattice constant and bulk modulus $B$ for each composition was determined by fitting the calculated ground state energy vs lattice parameter using the Murnaghan equation of state. The elastic constants $c_{11}$ and $c_{44}$ were determined by applying a $\pm 0-3 \%$ normal strain and a $0-7 \%$ shear strain, respectively, and fitting the energy vs strain curves with second order polynomials, while $c_{12}$ was obtained using $c_{12}=\left(3 B-c_{11}\right) / 2$ [59]. Curve fitting using higher order polynomials (up to order 6) to account for non-linear effects results in negligible corrections of $<3 \%$ in the calculated elastic constants. We note that no atomic relaxations are required for these calculations since the periodic boundary conditions and the relatively small 8atom unit cell result in all atoms occupying sites of point symmetry with zero net-force for relaxed and both normal and shear strained cells. However, for the $\mathrm{NbC}_{0.5} \mathrm{~N}_{0.5}$ unit cell, the two C atoms can occupy three different site combinations which, upon strain, lead to different C-C 
bond distances and angles and therefore values for the elastic constants that vary by $<1 \%,<1 \%$, and $7 \%$ for $c_{11}, c_{12}$, and $c_{44}$. The reported values for $\mathrm{NbC}_{0.5} \mathrm{~N}_{0.5}$ in this paper correspond to the average for the three configurations.

\section{RESULTS AND DISCUSSION}

Figure 1 is a plot of the measured layer composition as a function of deposition temperature $T_{s}=600$ to $1000{ }^{\circ} \mathrm{C}$. The $\mathrm{Nb}$ content is nearly unaffected by $T_{s}$ and ranges from $47-$ 49 at. \%. That is, the layers exhibit a nearly stoichiometric anion-to-cation ratio of $1.09 \pm 0.05$, suggesting that they consist primarily of solid solution $\mathrm{Nb}(\mathrm{N}, \mathrm{C})$ without considerable amorphous or graphitic $\mathrm{C}(\mathrm{N})$ inclusions that have previously been observed in polycrystalline $\mathrm{NbC}_{x} \mathrm{~N}_{y}$ layers [37]. The slight overstoichiometry can be attributed to interstitial $\mathrm{N}$ or $\mathrm{C}$ atoms and/or $\mathrm{Nb}$ vacancies that form due to implantation of energetic backscattered atoms and limited cation adatom mobility, respectively, similar to what has been reported for many other transition metal nitrides [44, 60, 61], but may also be attributed to possible carbon (or oxygen) surface contamination prior to EDS analyses. Therefore, we consider all layers in this study as stoichiometric within the experimental uncertainty of compositional analysis, and refer to them as $\mathrm{NbC}_{x} \mathrm{~N}_{1-x}$, where $x$ is the ratio of the $\mathrm{C}$ concentration over the total anion $(\mathrm{N}+\mathrm{C})$ concentration.

The $\mathrm{C}$ and $\mathrm{N}$ concentration are considerably affected by the deposition temperature. In particular, the $\mathrm{C}$ content increases from 9 to $10,16,18$ and 19 at. $\%$ for $T_{s}=600,700,800,900$ and $1000{ }^{\circ} \mathrm{C}$, respectively, while the $\mathrm{N}$ content simultaneously decreases from 44 to $42,36,33$ and 32 at. \%, yielding a considerable increase in the $\mathrm{C}$-to- $\mathrm{N}$ ratio from 0.20 to 0.59 . This compositional change occurs despite that the $\mathrm{Nb}$ and $\mathrm{C}$ fluxes, which are determined by the 
power to the sputtering sources, are kept constant. These results suggest that only a fraction of $\mathrm{C}$ atoms that impinge on the growth surface at $T_{s}=600{ }^{\circ} \mathrm{C}$ are incorporated in the deposited $\mathrm{NbC}_{x} \mathrm{~N}_{1-x}$ film, while increasing $T_{s}$ leads to a larger incorporation probability. We attribute this effect to a relatively high surface coverage (at low $T_{s}$ ) of adsorbed $\mathrm{N}_{2}$ molecules and atomic $\mathrm{N}$, where the latter forms through energetic $\mathrm{N}_{2}$ dissociation or direct $\mathrm{N}$ deposition from the plasma. The high nitrogen surface coverage is expected to cause a reduced $\mathrm{C}$ sticking coefficient $(<1)$, since $\mathrm{C}$ does not readily bond to $\mathrm{N}_{2}$ molecules, and/or desorption of C-containing molecules including CN-radicals or Cyanogen. Increasing $T_{s}$ leads to a reduction in the nitrogen coverage due to a higher rate of $\mathrm{N}_{2}$ recombination and desorption, as has been reported for the growth of various transition metal nitrides which form understoichiometric (N-deficient) layers if $T_{s} \geq$ $900{ }^{\circ} \mathrm{C}$ for $\mathrm{NbN}$ [19], $T_{s} \geq 730{ }^{\circ} \mathrm{C}$ for $\mathrm{CrN} \mathrm{[45],} T_{s} \geq 650{ }^{\circ} \mathrm{C}$ for $\mathrm{HfN}$ [44], and $T_{s} \geq 400{ }^{\circ} \mathrm{C}$ for TaN [42]. In particular, $\mathrm{NbN}_{x}(001)$ deposited in pure $\mathrm{N}_{2}$ is reported to be stoichiometric with $x=$ 0.95-0.98 for $T_{s} \leq 800{ }^{\circ} \mathrm{C}$ but nitrogen deficient with $x=0.81-0.91$ for $T_{s} \geq 900{ }^{\circ} \mathrm{C}$ [19]. As the $\mathrm{N}$-coverage decreases with increasing $T_{s}$, impinging $\mathrm{C}$ has a higher probability to physisorb, chemisorb, and ultimately incorporate in the growing $\mathrm{NbC}_{x} \mathrm{~N}_{1-x}$ film, leading to the increasing $\mathrm{C}$ concentration as shown in Fig. 1. The simultaneous decrease in N-concentration is, in turn, attributed to a reduced number of anion sites that are not already occupied by $\mathrm{C}$ atoms. The $\mathrm{N}_{2}$ flux impinging on the surface is approximately three orders of magnitudes larger than the $\mathrm{Nb}$ and C fluxes, such that there is always sufficient nitrogen to saturate remaining anion sites with nitrogen, under conditions where kinetic barriers for $\mathrm{N}_{2}$ dissociation and $\mathrm{N}$-incorporation are easily overcome.

Figure 2(a) shows typical $\theta-2 \theta$ XRD scans from $\mathrm{NbC}_{x} \mathrm{~N}_{1-x} / \mathrm{MgO}(001)$ layers deposited at $T_{s}=600,700,800,900$ and $1000{ }^{\circ} \mathrm{C}$. For clarity purposes, the scans are offset vertically and the 
intensity for $2 \theta<42.2^{\circ}$ multiplied by factors of 2 and 10 , as labeled. For $T_{s}=600{ }^{\circ} \mathrm{C}$, the only reflection that is detected over the entire measured $2 \theta$ range from $5-90^{\circ}$ is due to the substrate, yielding a double peak feature at $42.95^{\circ}$ and $43.06^{\circ}$ from $\mathrm{MgO} 002$ associated with the $\mathrm{Cu} \mathrm{K} \alpha_{1}$ and $\mathrm{K} \alpha_{2}$ lines. The small feature at $41.45^{\circ}$ which is present for all samples is an experimental artifact due to the line detector which causes an increased background intensity at $\pm 1.5^{\circ}$ off the strong substrate peak. The absence of a detectable peak from the layer indicates insufficient long-range crystalline order for detection by xrd. More specifically, we estimate that the average grain size is smaller than $3 \mathrm{~nm}$, since larger grains, even if randomly oriented, would yield detectable $x r d$ peak(s), based on the peak intensity detection limit for the given measurement setup of $100 \mathrm{cps}$. That is, $T_{s}=600{ }^{\circ} \mathrm{C}$ leads to a nanocrystalline microstructure which likely is the result of continuous grain renucleation during growth, caused by a high stacking defect density, similar to what has been reported for $\mathrm{NbN}$ growth at $T_{s} \leq 700{ }^{\circ} \mathrm{C}$ [19]. In contrast, the spectrum from the $\mathrm{NbC}_{x} \mathrm{~N}_{1-x}$ layer grown at $T_{s}=700{ }^{\circ} \mathrm{C}$ shows a well-developed peak at $41.21^{\circ}$. This peak is attributed to the 002 reflection of cubic $\mathrm{NbC}_{x} \mathrm{~N}_{1-x}$, since it is close to the reported 002 peak position for B1 structure $\mathrm{NbN}$ at $2 \theta=41.25^{\circ}$ (JCPDF 04-004-7058). The measured peak position yields an out-of-plane lattice constant along the growth direction of $a_{\perp}=4.382 \AA$. This is $0.11 \%$ larger than the reported $a_{\mathrm{NbN}}=4.377 \AA$, which is attributed to a lattice expansion due to the partial substitution of $\mathrm{N}$ by $\mathrm{C}$ on the anion sublattice, as discussed in more detail below. Increasing the growth temperature further to 800,900 , and $1000{ }^{\circ} \mathrm{C}$ results in a continuous shift in the xrd peak to lower $2 \theta$ values of $41.01^{\circ}, 40.95^{\circ}$, and $40.84^{\circ}$, respectively, as well as an increase in the peak intensity by approximately an order of magnitude, from $1.4 \times 10^{4}$ to $6.7 \times 10^{4}$ and $1.2 \times 10^{5} \mathrm{cps}$, suggesting an increasing crystalline quality with increasing $T_{s}$. We note here that the peak width remains, however, relatively broad even for $T_{s}=1000{ }^{\circ} \mathrm{C}$, 
indicating a considerable density of defects including threading dislocations associated with the large layer-substrate misfit as well as strain field variations. The full-width at half-height of $0.6^{\circ}$ for $T_{s}=1000{ }^{\circ} \mathrm{C}$ is at the high end of the range of peak widths, $0.14-0.7^{\circ}$, reported for ternary transition metal nitrides including $\mathrm{Ti}_{1-\mathrm{x}} \mathrm{W}_{\mathrm{x}} \mathrm{N}(001)$ [62], $\mathrm{Ti}_{1-\mathrm{x}} \mathrm{Sc}_{\mathrm{x}} \mathrm{N}(001)$ [3], and $\mathrm{Sc}_{1-\mathrm{x}} \mathrm{Al}_{\mathrm{x}} \mathrm{N}(001)$ [55]. In addition, the peaks in Fig. 2(a) are asymmetric, suggesting possible strain or composition variations over the thickness $(2.2 \pm 0.1 \mu \mathrm{m})$ of the films. We also note that the $45^{\circ}$ deposition angle which causes some increased shadowing may have a minor negative effect on the crystalline quality, as has been reported for the epitaxial growth of, for example, $\mathrm{CrN}(001)$ which forms some misoriented grains within an epitaxial matrix if grown from a very large deposition angle of $80^{\circ}$, while raising $T_{s}$ from 600 to $700{ }^{\circ} \mathrm{C}$ or reducing the deposition angle results in complete epitaxial $\mathrm{CrN}(001)$ layers [53, 63, 64].

Fig. 2(b) is a plot of the out-of-plane lattice constants $a_{\perp}$, as determined from the peak positions in Fig. 2(a) for $\mathrm{NbC}_{x} \mathrm{~N}_{1-x}$ layers deposited at $700-1000{ }^{\circ} \mathrm{C}$. The values are plotted against the composition $x$, as determined from the EDS analysis presented above. The $a_{\perp}$ values increase from $4.382 \pm 0.004 \AA$ for $x=0.19$ to $a_{\perp}=4.401 \pm 0.004,4.408 \pm 0.005$, and $4.419 \pm 0.005 \AA$ for $x=0.31,0.35$, and 0.37 , respectively. We attribute the increase in $a_{\perp}$ with increasing $\mathrm{C}$ concentration to the larger bond-length of $\mathrm{Nb}-\mathrm{C}$ vs $\mathrm{Nb}-\mathrm{N}$, which is due to the larger $2 p$ orbitals of $\mathrm{C}$ vs $\mathrm{N}$. This is also evident from the reported $\mathrm{NbC}$ lattice constant $a_{\mathrm{NbC}}=4.430 \AA$, which is $1.2 \%$ larger than $a_{\mathrm{NbN}}=4.377 \AA$. The values of these binary lattice constants $a_{\mathrm{NbN}}$ and $a_{\mathrm{NbC}}$ are also indicated in Fig. 2(b), as well as a linear interpolation $a_{\mathrm{int}}=a_{\mathrm{NbN}}+x\left(a_{\mathrm{NbC}}-a_{\mathrm{NbN}}\right)$ with a predicted slope $\mathrm{d} a / \mathrm{d} x=0.053 \AA$. The linear interpolation is justified, based on our first-principles predictions of $\mathrm{NbC}_{x} \mathrm{~N}_{1-x}$ lattice constants $a_{\mathrm{GGA}}$, which indicate a nearly linear increase with increasing $x=0,0.25,0.5,0.75$, and 1 , as presented in Table I. These values are predicted using 
the generalized gradient (GGA) approximation and are $0.96 \%$ and $1.17 \%$ larger than the experimental lattice constants reported for $\mathrm{NbN}$ and $\mathrm{NbC}$, respectively, which is attributed to the well known overestimation of lattice constants by the GGA [65]. Therefore, for easier direct comparison with experimental values, we account for the GGA overestimation by reducing the calculated lattice constants $a_{\mathrm{GGA}}$ of $\mathrm{NbC}_{x} \mathrm{~N}_{1-x}$ by a constant $1.07 \%$ to obtain the corrected values $a^{*}$, which are also presented in Table I and show good agreement with $a_{\text {int }}$. This is evident from the calculated data points for $x=0.25$ and 0.5 , which indicate a slope $\mathrm{d} a / \mathrm{d} x=0.060 \AA$ and are in excellent agreement with $a_{\text {int }}$ with $0.05 \%$ and $0.01 \%$ deviation, respectively, as shown in Fig. 2(b). In contrast, the experimentally measured out-of-plane lattice constant $a_{\perp}$ increases much steeper with $x$. This may be attributed to $T_{s}$-dependent residual strain in the deposited layers, as suggested by the reciprocal lattice map measurement presented and discussed below, yielding the $a_{\perp}, a_{\|}$, and $a_{\mathrm{o}}$ values for $T_{s}=1000^{\circ} \mathrm{C}$ which are also plotted in Fig. 2(b).

Figure 3 shows additional XRD results which are used to confirm epitaxy and determine the strain state of the $\mathrm{NbC}_{x} \mathrm{~N}_{1-x}$ layers. The plot in Fig. 3(a) is an XRD $\phi$-scan from the layer deposited at $T_{s}=1000{ }^{\circ} \mathrm{C}$ and is typical for all $\mathrm{NbC}_{x} \mathrm{~N}_{1-x}$ layers deposited at $T_{s}=700-1000{ }^{\circ} \mathrm{C}$. It is obtained using a parallel incident beam and setting $\omega$ and $2 \theta$ at fixed angles of $70.47^{\circ}$ and $60.47^{\circ}$, respectively, in order to detect the asymmetric 113 reflection from the $\mathrm{NbC}_{x} \mathrm{~N}_{1-x}$ layer which has its [001] direction aligned perpendicular to the substrate surface, as determined from the $\theta-2 \theta$ scan presented in Fig. 2(a). Sample rotation about the surface normal indicates a fourfold in-plane rotational symmetry with peaks at $\phi=0^{\circ}, \pm 90^{\circ}$, and $\pm 180^{\circ}$. The peaks occur at the same $\phi$-values as for scans (not shown) for which $\omega$ and $2 \theta$ values are adjusted to detect the substrate $\mathrm{MgO} 113$ reflections. This indicates that the $\mathrm{NbC}_{x} \mathrm{~N}_{1-x}$ layers are single crystals with a 
cube-on-cube epitaxial relationship to the substrate: $(001)_{\mathrm{NbCN}} \|(001)_{\mathrm{MgO}}$ and $[100]_{\mathrm{NbCN}} \|$ $[100]_{\mathrm{MgO}}$

Figure 3(b) is a reciprocal space map around an asymmetric 113 reflection obtained from the layer deposited at $T_{s}=1000{ }^{\circ} \mathrm{C}$. Diffracted intensity distributions are plotted as isointensity contours in reciprocal space where the reciprocal lattice vectors parallel and perpendicular to the surface are determined from the experimental $\omega$ and $2 \theta$ using $k_{\|}=2 \sin \theta \sin (\omega-\theta) / \lambda$ and $k_{\perp}=$ $2 \sin \theta \cos (\omega-\theta) / \lambda[66]$. The plot shows a maximum with $2.9 \times 10^{5}$ counts associated with the $\mathrm{MgO}$ 113 reflection, and a much weaker peak with 120 counts due to the $\mathrm{NbC}_{x} \mathrm{~N}_{1-x} 113$ reflection. The $\mathrm{MgO} 113$ peak is elongated along the $\omega$ direction, indicating some mosaicity with an estimated $0.04^{\circ}$ small angle grain boundary within the nominally single crystal $\mathrm{MgO}$ substrate. However, the substrate mosaicity is negligible in comparison to the width of the layer peak, which has a full-width at half-maximum along $\omega$ of $2.5^{\circ}$.

The in-plane $a_{\|}$and out-of-plane $a_{\perp}$ lattice parameters of the $\mathrm{NbC}_{x} \mathrm{~N}_{1-x}$ layer are determined from the 113 reflection using $a_{\|}=\sqrt{2} / k_{\|}$and $a_{\perp}=3 / k_{\perp}$, and setting the $\mathrm{MgO} 113$ peak within the reciprocal space to a position that corresponds to the relaxed lattice constant $a_{\mathrm{MgO}}=4.212 \AA$. This yields $a_{\|}=4.389 \pm 0.005 \AA$ and $a_{\perp}=4.417 \pm 0.006 \AA$ for this $\mathrm{NbC}_{0.37} \mathrm{~N}_{0.63}$ layer deposited at $T_{s}=1000{ }^{\circ} \mathrm{C}$. The latter value is in good agreement with $a_{\perp}=4.419 \pm 0.005 \AA$ from the $\theta-2 \theta$ scan presented above. We determine the relaxed lattice constant $a_{\mathrm{o}}=4.409 \pm 0.009$ $\AA$ using $a_{\mathrm{o}}=\left(a_{\perp}-v a_{\perp}+2 v a_{\|}\right) /(1+v)$, where $v=v_{100}=\mathrm{c}_{12} /\left(\mathrm{c}_{11}+\mathrm{c}_{12}\right)=0.17$ is the single-crystal Poisson ratio along [001] predicted for $\mathrm{NbC}_{0.25} \mathrm{~N}_{0.75}$. This value is relatively low in comparison to reported values of related transition metal nitrides $v_{\mathrm{ScN}}=0.20[67], v_{\mathrm{TiN}}=0.21[68], v_{\mathrm{Hf} 3 \mathrm{~N} 4}=$ $0.26[69]$ and $v_{\mathrm{CrN}}=0.29$ [70]. However, even a large uncertainty in $v$ of, for example, $50 \%$ has a negligible $(0.07 \%)$ impact on the measured $a_{0}$. The layer is in a state of compressive stress, with 
an in-plane biaxial strain $\varepsilon_{\|}=\left(a_{\|}-a_{\mathrm{o}}\right) / a_{\mathrm{o}}=-0.4 \%$. We attribute the residual compressive strain primarily to differential thermal contraction during cooling after deposition at $T_{s}=1000{ }^{\circ} \mathrm{C}$, while the relatively large layer-substrate lattice mismatch of $4.4 \%$ is expected to be nearly completely relaxed through misfit dislocations at the $\mathrm{MgO}-\mathrm{NbC}_{x} \mathrm{~N}_{1-x}$ interface. The reported thermal expansion coefficients for $\mathrm{MgO}, \mathrm{NbN}$, and $\mathrm{NbC}$ are $1.3 \times 10^{-5} \mathrm{~K}^{-1}, 10.1 \times 10^{-6} \mathrm{~K}^{-1}$ and $6.6 \times 10^{-6} \mathrm{~K}^{-1}$, respectively $[71,72]$. This results in an in-plane compressive strain of up to $-0.6 \%$ during cooling to room temperature, which is sufficient to completely account for the measured $-0.4 \%$. The layers deposited at $T_{s}<1000{ }^{\circ} \mathrm{C}$ are exposed to a smaller thermal contraction and are therefore expected to exhibit a smaller compressive strain, such that the measured $a_{\perp}$ values are closer to the relaxed lattice constant. Therefore, the steep slope of $a_{\perp}$ vs $T_{s}$ plotted in Fig. 2(b) may be due to the compounding effects of an increasing $a_{\mathrm{o}}$ associated with an increasing $\mathrm{C}$ concentration and an increasing compressive strain due to increasing thermal contraction during cooling after deposition. However, reciprocal lattice maps of these samples with $T_{s}<1000{ }^{\circ} \mathrm{C}$ did not yield sufficient intensity of the $113 \mathrm{NbC}_{x} \mathrm{~N}_{1-x}$ peak to accurately determine $a_{\|}$to confirm this interpretation.

Figure 4 is a plot of the measured hardness $H$ and elastic modulus $E$ of $\mathrm{NbC}_{x} \mathrm{~N}_{1-x}$ layers grown on $\mathrm{MgO}(001)$ as a function of $T_{s}$, as determined from nanoindentation measurements. The hardness increases from $18.2 \pm 0.8$ for $T_{s}=600{ }^{\circ} \mathrm{C}$ to $23.4 \pm 0.6 \mathrm{GPa}$ for $T_{s}=700{ }^{\circ} \mathrm{C}$, and remains approximately constant with $H=21.8 \pm 2.2,21.0 \pm 1.3$ and 22.9 $\pm 1.1 \mathrm{GPa}$ for $T_{s}=800,900$ and $1000{ }^{\circ} \mathrm{C}$. That is, the nanocrystalline microstructure of the layer grown at $T_{s}=600{ }^{\circ} \mathrm{C}$ results in a considerably lower hardness than that for the epitaxial single-crystals grown at $T_{s} \geq 700{ }^{\circ} \mathrm{C}$. In contrast, the increasing $\mathrm{C}$ concentration in the epitaxial $\mathrm{NbC}_{x} \mathrm{~N}_{1-x}$ layers from $x=0.19-0.37$ has negligible effect on $H$. The $H=22.9 \pm 1.1 \mathrm{GPa}$ of the best quality epitaxial $\mathrm{NbC}_{0.37} \mathrm{~N}_{0.63}$ layer 
deposited at $T_{s}=1000{ }^{\circ} \mathrm{C}$ is higher than $17.8 \pm 0.7 \mathrm{GPa}$ reported for nearly stoichiometric epitaxial $\mathrm{NbN}_{0.98}(001)$ [19], and is also larger than $H=20.0 \pm 0.8 \mathrm{GPa}$ for epitaxial $\mathrm{TiN}(001)$ [73] and 21.1 $\pm 1.1 \mathrm{GPa}$ for $\mathrm{ScN}(001)$ [39], but smaller than 25.2 $\pm 0.7 \mathrm{GPa}$ for epitaxial $\mathrm{HfN}(001)$ [43], 28.5 $\pm 1.0 \mathrm{GPa}$ for $\mathrm{CrN}(001)$ [45], 30.8 $\pm 0.9 \mathrm{GPa}$ for $\mathrm{TaN}(001)$ [74], and $27 \mathrm{GPa}$ for bulk single crystal $\mathrm{NbC}$ [75]. We note that the measured reduced hardness at small grain sizes is opposite to the expected trend from the well-established Hall-Petch relationship [76, 77], which predicts an increase in hardness with decreasing grain size. Leading to, for example, a higher hardness measured by nanoindentation for aluminum and aluminum-zirconium alloys [78], or an increasing hardness with increasing substrate temperature for PLD-grown $\mathrm{NbN}_{x}$ [79]. We attribute the opposite trend in our samples to (i) a possible porosity associated with a low adatom mobility for $T_{s}=600{ }^{\circ} \mathrm{C}$ or (ii) the inverse Hall-Petch relationship [80-82], which causes a decrease of the hardness for nanocrystalline microstructures with grain sizes typically below 10 $\mathrm{nm}$, consistent with the XRD results suggesting an average grain size $<3 \mathrm{~nm}$ for $T_{s}=600{ }^{\circ} \mathrm{C}$.

Figure 4(b) shows the measured elastic moduli obtained from the same set of indentations used to determine $H$. It remains approximately constant for $600{ }^{\circ} \mathrm{C} \leq T_{s} \leq 800{ }^{\circ} \mathrm{C}$ with $E=$ $339 \pm 11,351 \pm 8$ and $349 \pm 24 \mathrm{GPa}$ for $T_{s}=600,700$ and $800{ }^{\circ} \mathrm{C}$, respectively, but decreases slightly to $E=324 \pm 15 \mathrm{GPa}$ for $T_{s}=900{ }^{\circ} \mathrm{C}$ and then steeply to $E=284 \pm 7 \mathrm{GPa}$ for $T_{s}=1000{ }^{\circ} \mathrm{C}$. The reduction in $E$ at $T_{s} \geq 900{ }^{\circ} \mathrm{C}$ is not well understood, and may be related to anion vacancies near the surface that are not detected by the compositional analysis but are formed due to $\mathrm{N}_{2}$ recombination and desorption at high $T_{s}$, as discussed above. Based on this argument, we expect the average elastic modulus $E=350 \pm 12 \mathrm{GPa}$ from the epitaxial $\mathrm{NbC}_{x} \mathrm{~N}_{1-x}(001)$ layers with $T_{s}=$ $700-800{ }^{\circ} \mathrm{C}$ to most correctly reflect the intrinsic value. This value is larger than the reported $E=$ $315 \pm 13 \mathrm{GPa}$ for epitaxial $\mathrm{NbN}_{0.98}(001)$ [19] and $E=162-295 \mathrm{GPa}$ for nc-NbC/a-C films [24], 
but matches $E=346 \pm 6 \mathrm{GPa}$ for polycrystalline $\mathrm{NbC}_{1.99} \mathrm{~N}_{0.69}$ [37]. It is at the low end of the range reported for other epitaxial transition metal nitrides with $E=356 \pm 18 \mathrm{GPa}$ for $\mathrm{ScN}(001)$ [39], $E=$ $405 \pm 15 \mathrm{GPa}$ for $\mathrm{CrN}(001)$ [45], $E=445 \pm 38$ for $\mathrm{TiN}(001)$ [73], $E=450 \pm 9 \mathrm{GPa}$ [43] for $\mathrm{HfN}(001)$ and $457 \pm 16 \mathrm{GPa}$ for $\mathrm{TaN}(001)$ [74].

The calculated elastic constants of $\mathrm{NbC}_{x} \mathrm{~N}_{1-x}$ are listed in Table I. The bulk modulus is nearly independent of composition, decreasing slightly (by 2\%) from $307 \mathrm{GPa}$ for $\mathrm{NbN}$ to 300 GPa for NbC, suggesting a negligible change in "bond strength" as a function of $x$. Similarly, $c_{11}$ is nearly independent of $x$, increasing by just $4 \%$ from $\mathrm{NbN}$ to $\mathrm{NbC}$. In contrast, $c_{12}$ decreases by $16 \%$ and, most dramatically, $c_{44}$ increases by $119 \%$. This latter increase by more than a factor of two indicates a considerable increase in the resistance against shear deformation, suggesting an increase in the bond directionality with increasing $x$. This is also evident from the isotropic Poisson's ratio $v$, which is determined using $v=0.5-E / 6 B$ [83], where $E$ is the isotropic modulus discussed below. The Poisson's ratio decreases from 0.31 for $\mathrm{NbN}$ to 0.22 for $\mathrm{NbC}$. These changes suggest that the bonds in $\mathrm{NbC}_{x} \mathrm{~N}_{1-x}$ become more covalent and the compound becomes more brittle with increasing $x$, as also evident from Pugh's ratio $k=G / B$, where $G$ is the isotropic shear modulus. Pugh's ratio increases from $k=0.41$ for $\mathrm{NbN}$ to $k=0.69$ for NbC. Ductile materials typically exhibit $k<0.6$ and $v>0.25[84]$. Both conditions for ductility are satisfied for $\mathrm{NbN}$ but not for $\mathrm{NbC}$, confirming the trend towards a brittle material with increasing $x$.

The calculated isotropic elastic modulus $E$ is obtained using Hill's method [85] and is listed in Table I. It increases by $50 \%$ from $335 \mathrm{GPa}$ for $\mathrm{NbN}$ to $504 \mathrm{GPa}$ for $\mathrm{NbC}$. The predicted modulus for $\mathrm{NbC}_{0.25} \mathrm{~N}_{0.75}$ of $410 \mathrm{GPa}$ is $17 \%$ above the measured $350 \pm 12 \mathrm{GPa}$ for $x=0.19-0.31$, indicating reasonable agreement between experiment and calculations. Also, the calculations predict a $22 \%$ higher $E$ for $\mathrm{NbC}_{0.25} \mathrm{~N}_{0.75}$ than for $\mathrm{NbN}$, which is consistent, within experimental 
uncertainty, with the $11 \%$ increase obtained when comparing $E=351 \pm 8 \mathrm{GPa}$ measured for $\mathrm{NbC}_{0.19} \mathrm{~N}_{0.81}(001)$ with $E=315 \pm 13 \mathrm{GPa}$ reported for $\mathrm{NbN}_{0.98}(001)$ [19]. Here we note that the experimentally measured modulus does not exactly correspond to the isotropic modulus, since indentation is done along the [001] direction of an epitaxial layer, leading to a correction that depends on the anisotropy of the elastic constants, the indenter tip shape as well as its orientation relative to the in-plane crystalline orientation, as discussed in detail by Vlassak and Nix [86]. We estimate this effect to cause a 4-6\% correction in the measured values.

Figure 5 shows the resistivity $\rho$ of $\mathrm{NbC}_{x} \mathrm{~N}_{1-x}$ layers as a function of their growth temperature, measured both at room temperature $(295 \mathrm{~K})$ and $77 \mathrm{~K}$. The room temperature resistivity decreases from $\rho_{295 \mathrm{~K}}=892 \mu \Omega$-cm for $T_{s}=600{ }^{\circ} \mathrm{C}$ to a minimum $\rho_{295 \mathrm{~K}}=241 \mu \Omega$-cm for $T_{s}=800{ }^{\circ} \mathrm{C}$, and then remains relatively constant with $\rho_{295 \mathrm{~K}}=283$ and $272 \mu \Omega$-cm for $T_{s}=$ 900 to $1000{ }^{\circ} \mathrm{C}$, respectively. The data for $77 \mathrm{~K}$ shows a similar trend, decreasing from $\rho_{77 \mathrm{~K}}=$ 1185 to $277 \mu \Omega$-cm for $T_{s}=600-800{ }^{\circ} \mathrm{C}$, with $\rho_{77 \mathrm{~K}}=320$ and $312 \mu \Omega$-cm for $T_{s}=900$ and $1000{ }^{\circ} \mathrm{C}$. We attribute the high resistivity at $T_{s}=600{ }^{\circ} \mathrm{C}$ to the nanocrystalline microstructure, while the further decrease in $\rho$ from $T_{s}=700-800{ }^{\circ} \mathrm{C}$ is either due to (i) an improvement in the crystalline quality of these epitaxial layers or (ii) the increase in the C-concentration from $x=$ 0.19-0.31. In contrast, $\rho$ remains approximately constant for $T_{s}=800-1000{ }^{\circ} \mathrm{C}$. This latter temperature range corresponds to a relatively small change in composition from $x=0.31-0.37$, such that composition effects on the electron transport may be negligible. The resistivity at low temperature is higher for all layers, indicating that carrier localization effects dominate electron transport. A similar negative temperature coefficient of resistivity (TCR) has been reported for other epitaxial transition metal nitrides including $\operatorname{TaN}_{x}(001)$ [40], $\mathrm{Sc}_{1-x} \mathrm{Ti}_{x} \mathrm{~N}(001)$ [3], $\mathrm{Ti}_{1-x} \mathrm{~W}_{x} \mathrm{~N}(001)$ [62], $\mathrm{Sc}_{1-x} \mathrm{Al}_{x} \mathrm{~N}(001)$ [55], $\mathrm{CrN}(001)$ [51, 87], $\mathrm{HfN}_{x}(001)$ [44], and $\mathrm{NbN}_{x}$ [19], 
and is attributed to a weak Anderson localization of the conduction electrons associated with Nvacancies, anti-site substitutions, and random cation solid solutions. Consistent with this observation, we attribute the higher $\rho$ at $77 \mathrm{~K}$ for $\mathrm{NbC}_{x} \mathrm{~N}_{1-x} / \mathrm{MgO}(001)$ layers to a weak localization due to the random $\mathrm{N}$ and $\mathrm{C}$ distribution on anion sites.

\section{CONCLUSIONS}

A combination of experimental layer growth and first-principles density functional calculations are employed to study the rock-salt structure solid solution $\mathrm{NbC}_{x} \mathrm{~N}_{1-x}$. Co-sputtering from $\mathrm{Nb}$ and graphite targets in a $\mathrm{N}_{2}$ atmosphere leads to layers with a nearly stoichiometric anion-to- $\mathrm{Nb}$ ratio of $1.09 \pm 0.05$, suggesting a single phase $\mathrm{NbC}_{x} \mathrm{~N}_{1-x}$ compound. Increasing the deposition temperature $T_{s}$ from 600 to $1000{ }^{\circ} \mathrm{C}$ causes an increase in $x$ from 0.17 to 0.37 . This increase in the $\mathrm{C}$ concentration occurs without a change in the $\mathrm{C}$ deposition flux, indicating that the $\mathrm{C}$ sticking probability increases with increasing $T_{s}$, which is attributed to a decreasing $\mathrm{N}$ surface coverage on the growing layer surface. X-ray diffraction $\theta-2 \theta$ and $\phi$ scans show that layers grown on $\mathrm{MgO}(001)$ at $T_{s} \geq 700{ }^{\circ} \mathrm{C}$ are epitaxial single-crystals with a cube-on-cube relationship to the substrate, $(001)_{\mathrm{NbCN}} \|(001)_{\mathrm{MgO}}$ and $[100]_{\mathrm{NbCN}} \|[100]_{\mathrm{MgO}}$. Their out-of-plane lattice constant $a_{\perp}$ increases from $4.382 \AA$ for $x=0.19$ to $4.419 \AA$ for $x=0.37$. This increase is attributed to the larger bond-length of $\mathrm{Nb}-\mathrm{C}$ vs $\mathrm{Nb}-\mathrm{N}$, consistent with first-principles calculations that predict an approximately linear increase in the lattice constant with increasing $x$. However, the measured increase in $a_{\perp}$ is larger than the prediction, indicating an increasing compressive stress with increasing $T_{s}$. The residual strain is quantified using an XRD reciprocal space map for the $\mathrm{NbC}_{0.37} \mathrm{~N}_{0.63}$ layer deposited at $T_{s}=1000{ }^{\circ} \mathrm{C}$, yielding an in-plane compressive strain of $-0.4 \%$ and a relaxed lattice constant of $4.409 \pm 0.009 \AA$. The measured hardness of epitaxial 
$\mathrm{NbC}_{x} \mathrm{~N}_{1-x}(001)$ layers is $22 \pm 2 \mathrm{GPa}$, independent of $T_{s}=700-1000{ }^{\circ} \mathrm{C}$ and $x=0.19-0.37$. However, the $\mathrm{NbC}_{0.17} \mathrm{~N}_{0.83}$ layer deposited at $T_{s}=600{ }^{\circ} \mathrm{C}$ exhibits a nanocrystalline microstructure and a considerably lower hardness of $18.2 \pm 0.8 \mathrm{GPa}$. The elastic modulus is $350 \pm 12 \mathrm{GPa}$ for epitaxial layers with $T_{s}=700-800{ }^{\circ} \mathrm{C}$ but decreases to $284 \pm 7 \mathrm{GPa}$ as $T_{s}$ increases to $1000{ }^{\circ} \mathrm{C}$. The elastic modulus for $\mathrm{NbC}_{x} \mathrm{~N}_{1-x}(001)$ layers with $x=0.19-0.31$ is higher than for previously reported $\mathrm{NbN}_{0.98}$, consistent with the first-principles calculations that predict an increase in the isotropic elastic modulus from $335 \mathrm{GPa}$ for $\mathrm{NbN}$ to $504 \mathrm{GPa}$ for $\mathrm{NbC}$. The increase in $E$ is primarily due to an increase in $c_{44}$, which is due to an increase in the bond directionality with increasing $x$ and is expected to cause a transition from ductile $\mathrm{NbN}$ to brittle $\mathrm{NbC}$. The electrical resistivity of $\mathrm{NbC}_{x} \mathrm{~N}_{1-x}$ decreases with increasing $T_{s}<800{ }^{\circ} \mathrm{C}$, which is attributed to an increasing crystalline quality. It is higher at $77 \mathrm{~K}$ than at room temperature, indicating weak carrier localization due to the random distribution of $\mathrm{C}$ atoms on anion sites.

\section{ACKNOWLEDGEMENTS}

This research has been supported by the National Science Foundation with Grant Nos. 1309490, 1234777, and 1234872. Computational resources were provided by the Computational

Center for Nanotechnology Innovations at RPI. Kan Zhang thanks the Chinese Scholarship Council for financial support. 


\section{References}

[1] L. Hultman, Thermal stability of nitride thin films, Vacuum, 57 (2000) 1-30.

[2] J. Musil, Hard and superhard nanocomposite coatings, Surf. Coat. Technol.,, 125 (2000) 322-330.

[3] D. Gall, I. Petrov, J.E. Greene, Epitaxial Sc1-xTixN(001): Optical and electronic transport properties, J. Appl. Phys., 89 (2001) 401-409.

[4] U. Jansson, E. Lewin, Sputter deposition of transition-metal carbide films - A critical review from a chemical perspective, Thin Solid Films, 536 (2013) 1-24.

[5] Z.T.Y. Liu, X. Zhou, D. Gall, S.V. Khare, First-principles investigation of the structural, mechanical and electronic properties of the $\mathrm{NbO}$-structured $3 \mathrm{~d}, 4 \mathrm{~d}$ and $5 \mathrm{~d}$ transition metal nitrides, Computational Materials Science, 84 (2014) 365-373.

[6] Z.T.Y. Liu, X. Zhou, S.V. Khare, D. Gall, Structural, mechanical and electronic properties of 3d transition metal nitrides in cubic zincblende, rocksalt and cesium chloride structures: a first-principles investigation, Journal of Physics-Condensed Matter, 26 (2014) 025404.

[7] K.S. Keskar, T. Yamashita, Y. Onodera, Superconducting Transition Temperatures of R. F. Sputtered NbN Films, Japan. J. Appl. Phys., 10 (1971) 370-374.

[8] E.V. Pechen, S.I. Krasnosvobodtsev, N.P. Shabanova, E.V. Ekimov, A.V. Varlashkin, V.S. Nozdrin, A.M. Tschovrebov, A.I. Golovashkin, Tunneling and critical-magnetic-field study of superconducting NbC thin films, Physica C: Superconductivity, 235-240 (1994) 2511-2512.

[9] Z. Wang, H. Terai, A. Kawakami, Y. Uzawa, Interface and tunneling barrier heights of NbN/AlN/NbN tunnel junctions, Appl. Phys. Lett., 75 (1999) 701.

[10] G.N. Goltsman, O. Okunev, G. Chulkova, A. Lipatov, A.Semenov, K. Smirnov, B. Voronov, A. Dzardanov, C. Williams, R. Sobolewski, Picosecond superconducting single-photon optical detector, Appl. Phys. Lett., 79 (2001) 705.

[11] T. Amriou, B. Bouhafs, H. Aourag, B. Khelifa, S. Bresson, C. Mathieu, FP-LAPW investigations of electronic structure and bonding, Phys. B: Condens. Matter, 325 (2003) 44-56.

[12] Y. Saito, S. Kawata, H. Nakane, H. Adachi, Emission characteristics of niobium nitride field emitters, Appl. Surf. Sci. , 146 (1999) 177-181.

[13] A. Gubernat, Journal of the European Ceramic Society, 33 (2013) 2391-2398.

[14] A. Bendavid, P.J. Martin, T.J. Kinder, E.W. Preston, Properties of Ti1-xSixNy films deposited by concurrent cathodic arc evaporation and magnetron sputtering, Surf. Coat. Technol.,, 163-164 (2003) 347352.

[15] M.A. Mamun, A.H. Farha, A.O. Er, Y. Ufuktepe, D. Gu, H.E. Elsayed-Ali, A.A. Elmustafa, Nanomechanical properties of $\mathrm{NbN}$ films prepared by pulsed laser deposition using nanoindendation, Appl. Surf. Sci., 258 (2012) 4308-4313.

[16] Z.H. Han, X.P. Hu, J.W. Tian, G.Y. Li, M.Y. Gu, Magnetron sputtered NbN thin films and mechanical properties, Surf. Coat. Technol., 179 (2004) 188-192.

[17] M. Benkahoul, E. Martinez, A. Karimi, R. Sanjinés, F. Lévy, Structural and mechanical properties of sputtered cubic and hexagonal NbNx thin films, Surf. Coat. Technol.,, 180-181 (2004) 178-183.

[18] M. Wen, C.Q. Hu, C. Wang, T. An, Y.D. Su, Q.N. Meng, W.T. Zheng, Effects of substrate bias on the preferred orientation, phase transition and mechanical properties for $\mathrm{NbN}$ films grown by direct current reactive magnetron sputtering, J. Appl. Phys., 104 (2008) 023527.

[19] K. Zhang, K. Balasubramanian, B.D. Ozsdolay, C.P. Mulligan, S.V. Khare, W.T. Zheng, D. Gall, Growth and physical properties of epitaxial $\mathrm{NbN}(001)$ films on $\mathrm{MgO}(001)$, Thin Solid Films, DOI (2015) (under review).

[20] K. Zhang, M. Wen, Q.N. Meng, C.Q. Hu, X. Li, C. Liu, W.T. Zheng, Effects of substrate bias voltage on the microstructure, mechanical properties and tribological behavior of reactive sputtered niobium carbide films, Surface and Coatings Technology, 212 (2012) 185-191.

[21] K. Zhang, M. Wen, G. Cheng, X. Li, Q.N. Meng, J.S. Lian, W.T. Zheng, Reactive magnetron sputtering deposition and characterization of niobium carbide films, Vacuum, 99 (2014) 233-241. 
[22] M. Torche, G. Schmerber, M. Guemmaz, A. Mosser, J.C. Parlebas, Non-stoichiometric niobium nitrides: structure and properties, Thin Solid Films, 436 (2003) 208-212.

[23] P. Alen, M. Ritala, K. Arstila, J. Keinonen, M. Leskela, The growth and diffusion barrier properties of atomic layer deposited NbNx thin films, Thin Solid Films, 491 (2005) 235-241.

[24] N. Nedfors, O. Tengstrand, E. Lewin, A. Furlan, P. Eklund, L. Hultman, U. Jansson, Structural, mechanical and electrical-contact properties of nanocrystalline-NbC/amorphous- $\mathrm{C}$ coatings deposited by magnetron sputtering, Surface and Coatings Technology, 206 (2011) 354-359.

[25] C. Weia, J.F. Lin, T.-H. Jiangb, C.-F. Ai, Tribological characteristics of titanium nitride and titanium carbonitride multilayer films Part II. The effect of coating sequence on tribological properties, Thin Solid Films, 381 (2001) 104-118.

[26] D.K. Merl, P. Panjan, M. Cekada, M. Macek, The corrosion behavior of Cr-(C,N) PVD hard coatings deposited on various substrates, Electrochimica Acta, 49 (2004) 1527-1533.

[27] E. Silva, M. Rebelo de Figueiredo, R. Franz, R. Escobar Galindo, C. Palacio, A. Espinosa, S.

Calderon V, C. Mitterer, S. Carvalho, Structure-property relations in $\mathrm{ZrCN}$ coatings for tribological applications, Surface and Coatings Technology, 205 (2010) 2134-2141.

[28] R. Chen, J.P. Tu, D.G. Liu, Y.J. Mai, C.D. Gu, Microstructure, mechanical and tribological properties of TiCN nanocomposite films deposited by DC magnetron sputtering, Surface and Coatings Technology, 205 (2011) 5228-5234.

[29] S.H. Yao, Y.L. Su, W.H. Kao, K.W. Cheng, Wear behavior of DC unbalanced magnetron sputter deposited ZrCN films, Materials Letters, 59 (2005) 3230-3233.

[30] B. Warcholinski, A. Gilewicz, Effect of substrate bias voltage on the properties of $\mathrm{CrCN}$ and $\mathrm{CrN}$ coatings deposited by cathodic arc evaporation, Vacuum, 90 (2013) 145-150.

[31] R. Ospina, D. Escobar-Rincón, P.J. Arango, E. Restrepo-Parra, J.F. Jurado, Structural and chemical composition analysis of WCN produced by pulsed vacuum arc discharge, Surface and Coatings

Technology, 232 (2013) 96-100.

[32] Q. Liu, T. Liu, Q.F. Fang, F.J. Liang, J.X. Wang, Preparation and characterization of nanocrystalline composites Mo-C-N hard films, Thin Solid Films, 503 (2006) 79-84.

[33] B.T. Matthias, TRANSITION TEMPERATURES OF SUPERCONDUCTORS, Physical Review, 92 (1953) 874-876.

[34] T.L. Francavilla, S.A. Wolf, E.F. Skelton, Superconducting properties of reactively sputtered NbCN thin films, IEEE Trans. Magn., 17 (1981) 569.

[35] E.F. Skelton, S.A. Wolf, T.L. Francavilla, STRUCTURAL CHARACTERIZATION OF NbCN THIN-FILMS, Journal of Vacuum Science \& Technology, 18 (1981) 259-261.

[36] L.J. Lin, D.E. Prober, Superconducting NbNxCy thin films fabricated with a dual ion-beam sputtering method, Appl. Phys. Lett. , 49 (1986) 416.

[37] K. Zhang, M. Wen, S. Wang, R.P. Deng, D. Gall, W.T. Zheng, Sputter deposited NbCxNy films:

Effect of nitrogen content on structure and mechanical and tribological properties, Surf. Coat. Technol., 258 (2014) 746-753.

[38] C.S. Shin, S. Rudenja, D. Gall, N. Hellgren, T.Y. Lee, I. Petrov, J.E. Greene, Growth, surface morphology, and electrical resistivity of fully strained substoichiometric epitaxial TiNx $(0.67<=\mathrm{x}<1.0)$ layers on $\mathrm{MgO}(001)$, J. Appl. Phys., 95 (2004) 356-362.

[39] D. Gall, I. Petrov, N. Hellgren, L. Hultman, J.E. Sundgren, J.E. Greene, Growth of poly- and singlecrystal $\mathrm{ScN}$ on $\mathrm{MgO}$ (001): Role of low-energy $\mathrm{N}-2(+)$ irradiation in determining texture, microstructure evolution, and mechanical properties, J. Appl. Phys., 84 (1998) 6034-6041.

[40] C.S. Shin, D. Gall, Y.W. Kim, P. Desjardins, I. Petrov, J.E. Greene, M. Oden, L. Hultman, Epitaxial $\mathrm{NaCl}$ structure delta- $\mathrm{TaNx}(001)$ : Electronic transport properties, elastic modulus, and hardness versus N/Ta ratio, J. Appl. Phys., 90 (2001) 2879-2885.

[41] C.S. Shin, Y.W. Kim, D. Gall, J.E. Greene, I. Petrov, Phase composition and microstructure of polycrystalline and epitaxial TaNx layers grown on oxidized $\mathrm{Si}(001)$ and $\mathrm{MgO}(001)$ by reactive magnetron sputter deposition, Thin Solid Films, 402 (2002) 172-182. 
[42] C.S. Shin, Y.W. Kim, N. Hellgren, D. Gall, I. Petrov, J.E. Greene, Epitaxial growth of metastable delta-TaN layers on $\mathrm{MgO}(001)$ using low-energy, high-flux ion irradiation during ultrahigh vacuum reactive magnetron sputtering, J. Vac. Sci. Technol. A-Vac. Surf. Films, 20 (2002) 2007-2017.

[43] H.S. Seo, T.Y. Lee, J.G. Wen, I. Petrov, J.E. Greene, D. Gall, Growth and physical properties of epitaxial HfN layers on MgO(001), J. Appl. Phys., 96 (2004) 878-884.

[44] H.S. Seo, T.Y. Lee, I. Petrov, J.E. Greene, D. Gall, Epitaxial and polycrystalline HfNx $(0.8<=x<=$ 1.5) layers on $\mathrm{MgO}(001)$ : Film growth and physical properties, J. Appl. Phys., 97 (2005) 083521.

[45] D. Gall, C.S. Shin, T. Spila, M. Oden, M.J.H. Senna, J.E. Greene, I. Petrov, Growth of single-crystal $\mathrm{CrN}$ on $\mathrm{MgO}(001)$ : Effects of low-energy ion-irradiation on surface morphological evolution and physical properties, J. Appl. Phys., 91 (2002) 3589-3597.

[46] T.Y. Lee, D. Gall, C.S. Shin, N. Hellgren, I. Petrov, J.E. Greene, Growth and physical properties of epitaxial CeN layers on MgO(001), J. Appl. Phys., 94 (2003) 921-927.

[47] X.Y. Zhang, D. Gall, CrN electronic structure and vibrational modes: An optical analysis, Phys. Rev. B, 82 (2010) 045116.

[48] J.M. Purswani, T. Spila, D. Gall, Growth of epitaxial $\mathrm{Cu}$ on $\mathrm{MgO}(001)$ by magnetron sputter deposition, Thin Solid Films, 515 (2006) 1166-1170.

[49] J.S. Chawla, X.Y. Zhang, D. Gall, Effective electron mean free path in TiN(001), J. Appl. Phys., 113 (2013) 063704.

[50] M.A. Wall, D.G. Cahill, I. Petrov, D. Gall, J.E. Greene, Nucleation kinetics during homoepitaxial growth of TiN(001) by reactive magnetron sputtering, Phys. Rev. B, 70 (2004) 035413.

[51] X.Y. Zhang, J.S. Chawla, B.M. Howe, D. Gall, Variable-range hopping conduction in epitaxial CrN(001), Phys. Rev. B, 83 (2011) 165205.

[52] X.Y. Zhang, D. Gall, Surface mound formation during epitaxial growth of CrN(001), Thin Solid Films, 518 (2010) 3813-3818.

[53] J.R. Frederick, J. D'Arcy-Gall, D. Gall, Growth of epitaxial CrN on $\mathrm{MgO}(001)$ : Role of deposition angle on surface morphological evolution, Thin Solid Films, 494 (2006) 330-335.

[54] R. Deng, B.D. Ozsdolay, P.Y. Zheng, S.V. Khare, D. Gall, Optical and transport measurement and first-principles determination of the ScN band gap, Phys. Rev. B, 91 (2015) 045104.

[55] R. Deng, P.Y. Zheng, D. Gall, Optical and electron transport properties of rock-salt Sc1-xAlxN, J. Appl. Phys., 118 (2015) 015706.

[56] W.C. Oliver, G.M. Pharr, Measurement of hardness and elastic modulus by instrument indentation advances in understanding and refinement to methodology, Journal of Materials Research, 19 (2004) 3-20. [57] J.P. Perdew, K. Burke, M. Ernzerhof, Generalized Gradient Approximation Made Simple, Phys. Rev. Lett., 77 (1996) 3865.

[58] J.P. Perdew, J.A. Chevary, S.H. Vosko, K.A. Jackson, M.R. Pederson, D.J. Singh, C. Fiolhais, Atoms, molecules, solids, and surfaces: Applications of the generalized gradient approximation for exchange and correlation, Phys. Rev. B, 46 (1992) 6671.

[59] Z.T.Y. Liu, D. Gall, S.V. Khare, Electronic and bonding analysis of hardness in pyrite-type transition-metal pernitrides, Phys. Rev. B, 90 (2014) 134102.

[60] M. Wen, Q.N. Meng, W.X. Yu, W.T. Zheng, S.X. Mao, M.J. Hua, Surface and Coatings Technology, 205 (2010) 1953-1961.

[61] J.-E. Sundgren, B.O. Jahansson, A. Rockett, S.A. Barnett, J.E. Greene, Physics and Chemistry of Protective Coatings, American Institute of Physics Conference Proceedinds, 149 (1986) 95-115.

[62] F. Tian, J. D'Arcy-Gall, T.Y. Lee, M. Sardela, D. Gall, I. Petrov, J.E. Greene, Epitaxial $\mathrm{Ti}_{1-\mathrm{x}} \mathrm{W}_{\mathrm{x}} \mathrm{N}$ alloys grown on $\mathrm{MgO}(001)$ by ultrahigh vacuum reactive magnetron sputtering: Electronic properties and long-range cation ordering, J. Vac. Sci. Technol. A, 21 (2003) 140-146.

[63] J.R. Frederick, D. Gall, Surface morphological evolution of epitaxial $\mathrm{CrN}(001)$ layers, J. Appl. Phys., 98 (2005) 054906.

[64] J.R. Frederick, D. Gall, Nanostaircases: An atomic shadowing instability during epitaxial CrN(001) layer growth, Appl. Phys. Lett., 87 (2005) 053107. 
[65] J. Paier, M. Marsman, K. Hummer, G. Kresse, I.C. Gerber, J.G. Ángyán, Screened hybrid density functionals applied to solids, The Journal of Chemical Physics, 124 (2006) 154709.

[66] P.v.d. Sluis, Determination of strain in epitaxial semiconductor layers by high-resolution X-ray diffraction, J. Phys. D: Appl. Phys., 26 (1993) A188.

[67] D. Gall, I. Petrov, P. Desjardins, J.E. Greene, Microstructural evolution and Poisson ratio of epitaxial ScN grown, J. Appl. Phys., 86 (1999) 5524-5529.

[68] J.O. Kim, J.D. Aschenbach, P.B. Mirkarimi, M. Shinn, S.A. Barnett, Elastic constants of single crystal transition metal nitride films measured by line focus acoustic microscopy, J. Appl. Phys., 72 (1992) 1805.

[69] P. Kroll, Hafnium nitride with thorium phosphide structure: Physical properties and an assessment of the $\mathrm{Hf}-\mathrm{N}, \mathrm{Zr}-\mathrm{N}$, and $\mathrm{Ti}-\mathrm{N}$ phase diagrams at high pressures and temperatures, Phys. Rev. Lett., 90 (2003) 125501 .

[70] U. Wiklund, M. Bromark, M. Larsson, P. Hedenqvist, S. Hogmark, Cracking resistance of thin hard coatings estimated by four-point bending, Surf. Coat. Technol., 91 (1997) 57-63.

[71] H.O.R.C.A.N. H. Pierson, (Noyes Publications, USA, 1996), DOI.

[72] H.L.a. R.Bornstein, Numerical Data and Functional Relationships in Science and Technology, Group III (Springer, Berlin, 1975) Vol.7, Pt. b1, p. 27, DOI.

[73] H. Ljungcrantz, M. Odén, L. Hultman, J.E. Greene, J.-E. Sundgren, Nanoindentation studies of single crystal (001), (011), and (111) oriented TiN layers on MgO, J. Appl. Phys., 80 (1996) 6725.

[74] C.S. Shin, D. Gall, P. Desjardins, A. Vailionis, H. Kim, I. Petrov, J.E. Greene, M. Oden, Growth and physical properties of epitaxial metastable cubic TaN(001), Appl. Phys. Lett., 75 (1999) 3808-3810.

[75] P. Ettmayer, i.R.B.K.E. W. Lengauer, Carbides: Transition Metal Solid State Chemistry, John Wiley \& Sons Ltd., Chichester, DOI (1994).

[76] E.O. Hall, The Deformation and Aging of Mild Steel, Proceedings of the Physical Society of London Section B, 64 (1951) 747-753.

[77] N.J. Petch, The Cleavage Strength of Polycrystals, Journal of the Iron and Steel Institute, 174 (1953) 25-28.

[78] A.A. Elmustafa, J.A. Eastman, M.N. Rittner, J.R. Weertman, D.S. Stone, Indentation size effect: Large grained aluminum versus nanocrystalline aluminum-zirconium alloys, Scripta Materialia, 43 (2000) 951-955.

[79] M.A. Al Mamun, A.H. Farha, Y. Ufuktepe, H.E. Elsayed-Ali, A.A. Elmustafa, Investigation of the crystal structure on the nanomechanical properties of pulsed laser deposited niobium nitride thin films, Journal of Materials Research, 27 (2012) 1725-1731.

[80] T.G. Nieh, J. Wadsworth, Hall-Petch Relation in Nanocrystalline Solids, Scr. Metall. Materialia, 25 (1991) 955-958.

[81] G.J. Fan, H. Choo, P.K. Liaw, E.J. Lavernia, Plastic deformation and fracture of ultrafine-grained AlMg alloys with a bimodal grain size distribution, Acta Materialia, 54 (2006) 1759-1766.

[82] C.P. Mulligan, R. Wei, G. Yang, P. Zheng, R. Deng, D. Gall, Microstructure and age hardening of C276 alloy coatings, Surf. Coat. Technol., 270 (2015) 299-304.

[83] J.M.J.d. Toonder, J.A.W.v. Dommelen, F. Baaijens, The relation between single crystal elasticity and the effective elastic behaviour of polycrystalline materials: theory, measurement and computation,

Modelling Simul. Mater. Sci. Eng. , 7 (1999) 909-928.

[84] S.F. Pugh, RELATIONS BETWEEN THE ELASTIC MODULI AND THE PLASTIC

PROPERTIES OF POLYCRYSTALLINE PURE METALS, Philosophical Magazine, 45 (1954) 823-843. [85] R. Hill, THE ELASTIC BEHAVIOUR OF A CRYSTALLINE AGGREGATE, Proceedings of the Physical Society of London Section A, 65 (1952) 349-355.

[86] J.J. Vlassak, W.D. Nix, Indentation modulus of elastically anisotropic half spaces, Philosophical Magazine A, 67 (1993) 1045-1056.

[87] X.Y. Zhang, J.S. Chawla, R.P. Deng, D. Gall, Epitaxial suppression of the metal-insulator transition in CrN, Phys. Rev. B, 84 (2011) 073101. 


\section{Tables}

$\begin{array}{lcccccccc}\text { Composition } & \begin{array}{c}a_{\mathrm{GGA}} \\ (\AA)\end{array} & \begin{array}{c}a^{*} \\ (\AA)\end{array} & \begin{array}{c}B \\ (\mathrm{GPa})\end{array} & \begin{array}{c}c_{11} \\ (\mathrm{GPa})\end{array} & \begin{array}{c}c_{12} \\ (\mathrm{GPa})\end{array} & \begin{array}{c}c_{44} \\ (\mathrm{GPa})\end{array} & \begin{array}{c}E \\ (\mathrm{GPa})\end{array} & v \\ \mathrm{NbN} & 4.419 & 4.372 & 307 & 641 & 140 & 78 & 335 & 0.31 \\ \mathrm{NbC}_{0.25} \mathrm{~N}_{0.75} & 4.435 & 4.388 & 305 & 654 & 130 & 115 & 410 & 0.27 \\ \mathrm{NbC}_{0.5} \mathrm{~N}_{0.5} & 4.450 & 4.403 & 303 & 660 & 124 & 133 & 442 & 0.25 \\ \mathrm{NbC}_{0.75} \mathrm{~N}_{0.25} & 4.467 & 4.420 & 301 & 664 & 120 & 158 & 484 & 0.23 \\ \mathrm{NbC} & 4.482 & 4.435 & 300 & 666 & 117 & 171 & 504 & 0.22\end{array}$

Table 1: Results from first-principles calculations on $\mathrm{NbC}_{x} \mathrm{~N}_{1-x}$ with $x=0,0.25,0.5,0.75,1$, including the as-calculated $a_{\mathrm{GGA}}$ and corrected $a^{*}=0.98944 \times a_{\mathrm{GGA}}$ lattice constants, the bulk modulus $B$, the elastic constants $c_{11}, c_{12}$, and $c_{44}$, and the isotropic elastic modulus $E$ and isotropic Poisson's ratio $v$. 


\section{Figure Captions}

Fig.1. The composition of $\mathrm{NbC}_{x} \mathrm{~N}_{1-x}$ films as a function of deposition temperature $T_{s}=600$ $1000{ }^{\circ} \mathrm{C}$.

Fig.2. (a) X-ray diffraction $\theta-2 \theta$ scans for $T_{s}=600-1000{ }^{\circ} \mathrm{C}$ and (b) out-of-plane lattice parameter $a_{\perp}$ for epitaxial $\mathrm{NbC}_{x} \mathrm{~N}_{1-x}$ layers as a function of $x$. The plot also includes, as open symbols, the in-plane $a_{\|}$, out-of-plane $a_{\perp}$, and relaxed $a_{\mathrm{o}}$ lattice parameters obtained from the reciprocal space map in Fig. 3(b) for $T_{s}=1000^{\circ} \mathrm{C}$. The dashed lines indicate the reported lattice constants for $\mathrm{NbN}$ (JCPDF 04-004-7058) and $\mathrm{NbC}$ (JCPDF 65-8781) and their linear interpolation $a_{\text {int, }}$ while the data points at $x=0.25$ and 0.5 are the calculated values $a^{*}$ listed in Table I.

Fig.3. X-ray diffraction (a) $\phi$-scan of 113 reflections and (b) reciprocal space map around the 113 reflections, from a $\mathrm{NbC}_{0.37} \mathrm{~N}_{0.63}(001) / \mathrm{MgO}(001)$ layer deposited at $T_{s}=1000{ }^{\circ} \mathrm{C}$.

Fig.4. (a) Hardness $H$ and (b) elastic modulus $E$, of $\mathrm{NbC}_{x} \mathrm{~N}_{1-x} / \mathrm{MgO}(001)$ layers deposited at $T_{s}=$ $600-1000{ }^{\circ} \mathrm{C}$.

Fig. 5. Resistivity $\rho$ measured at room temperature $(295 \mathrm{~K})$ and $77 \mathrm{~K}$, of $\mathrm{NbC}_{x} \mathrm{~N}_{1-x} / \mathrm{MgO}(001)$ layers deposited at $T_{s}=600-1000{ }^{\circ} \mathrm{C}$. 


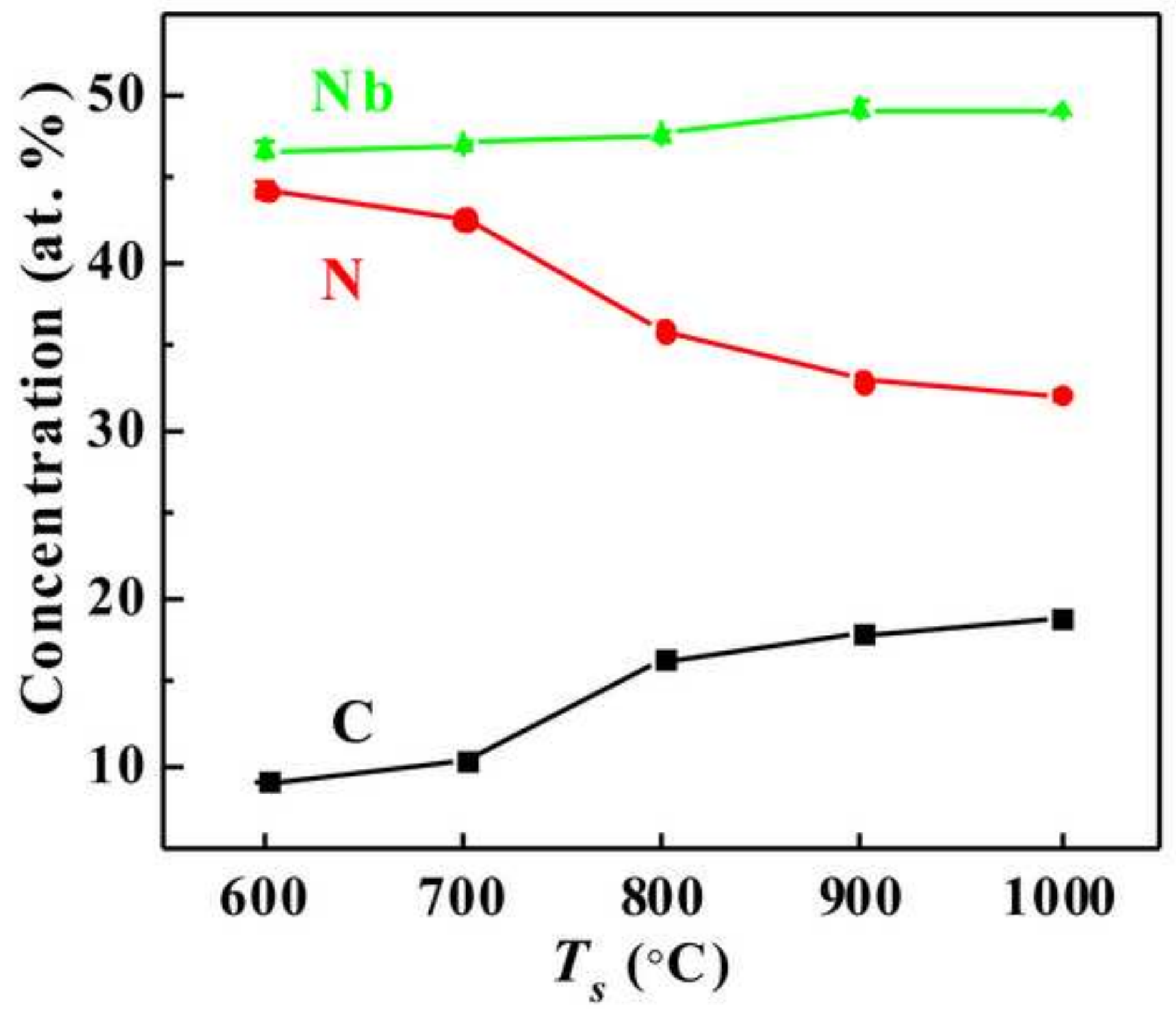



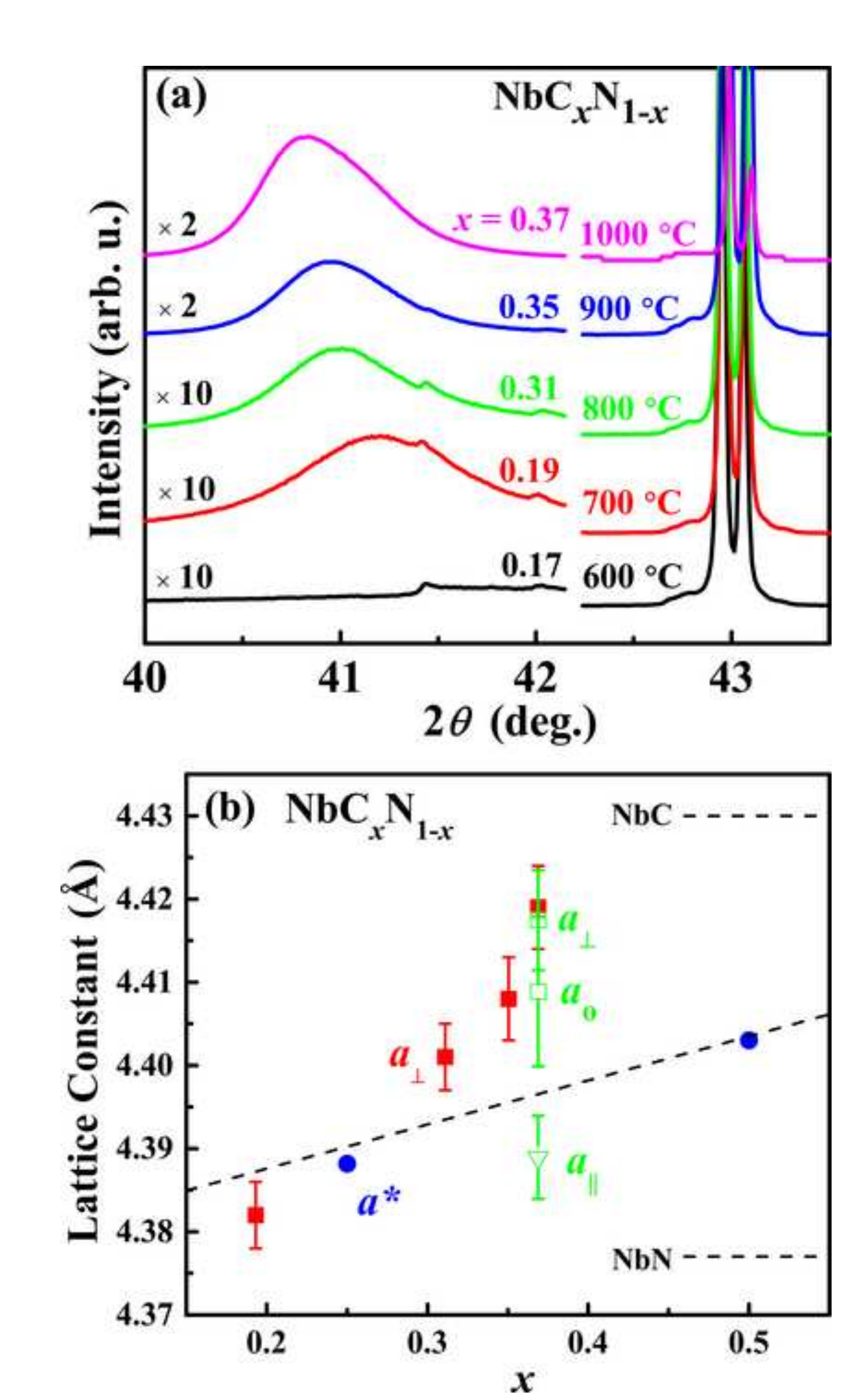

Figure2

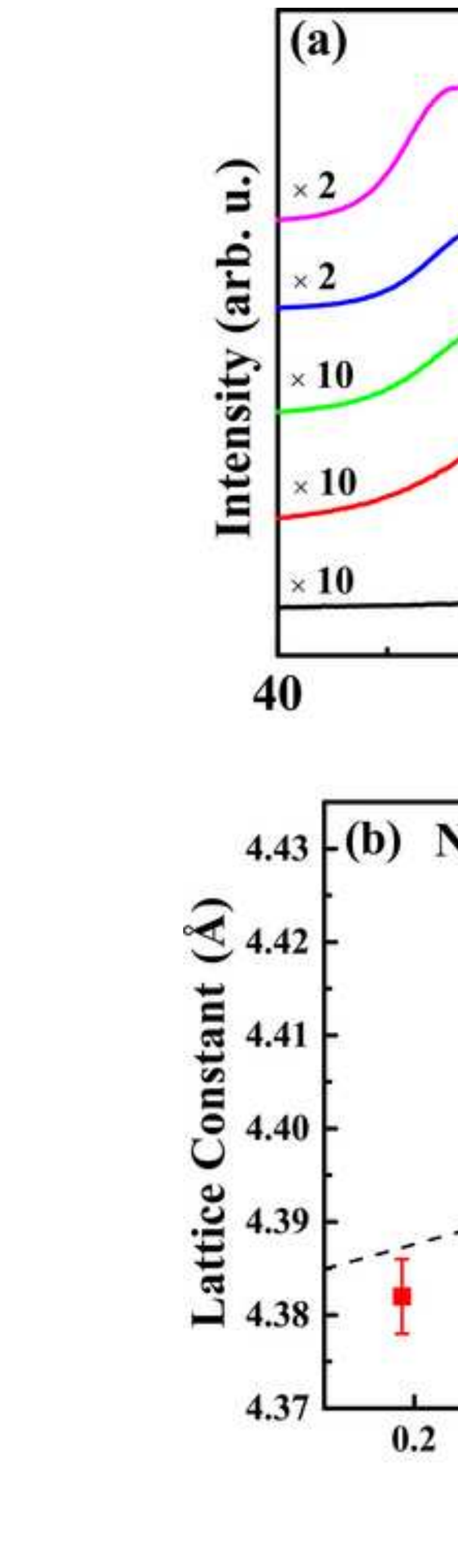

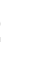



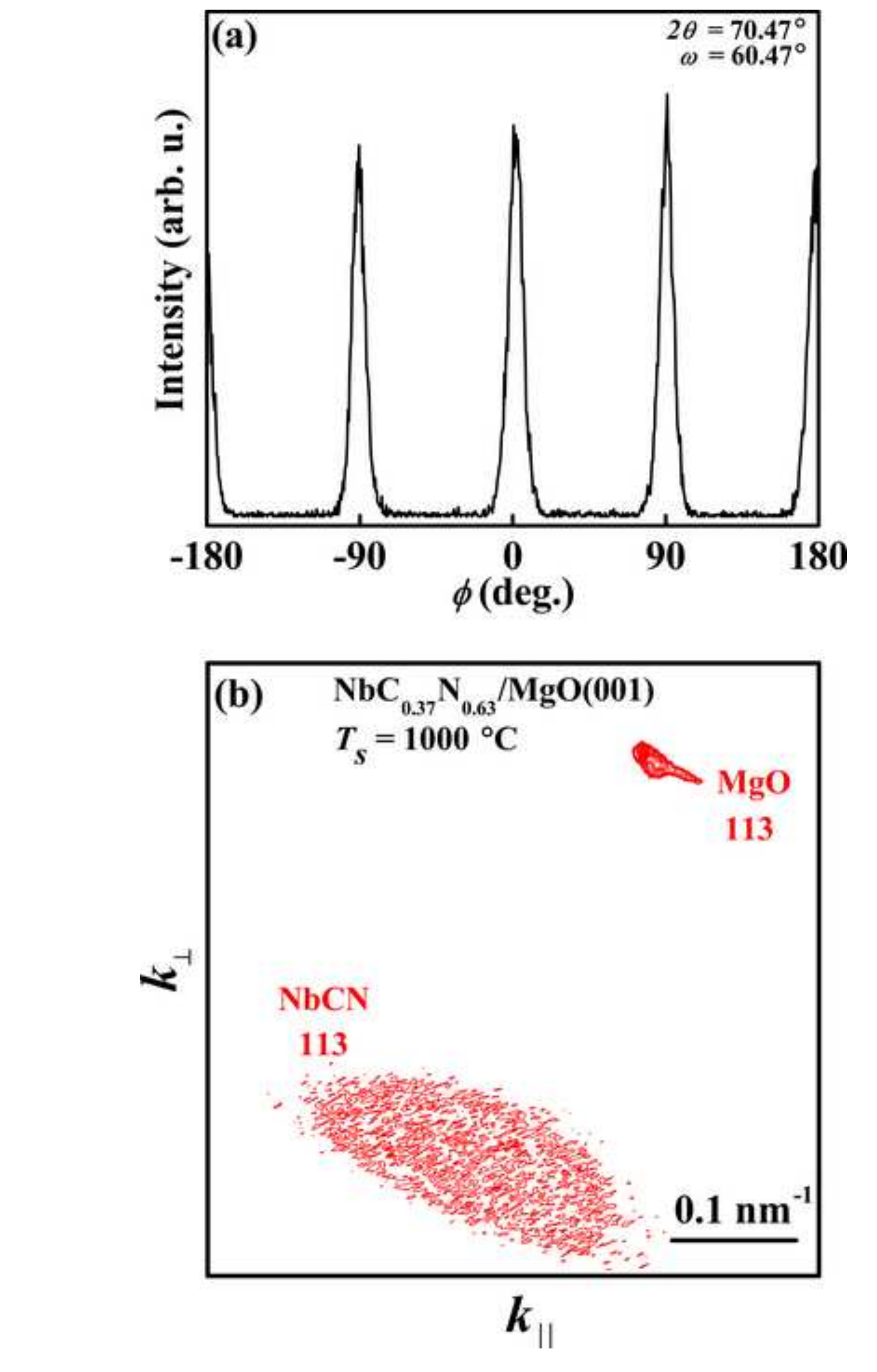

Figure 3

(1)

-
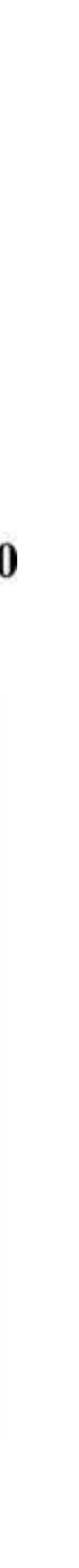


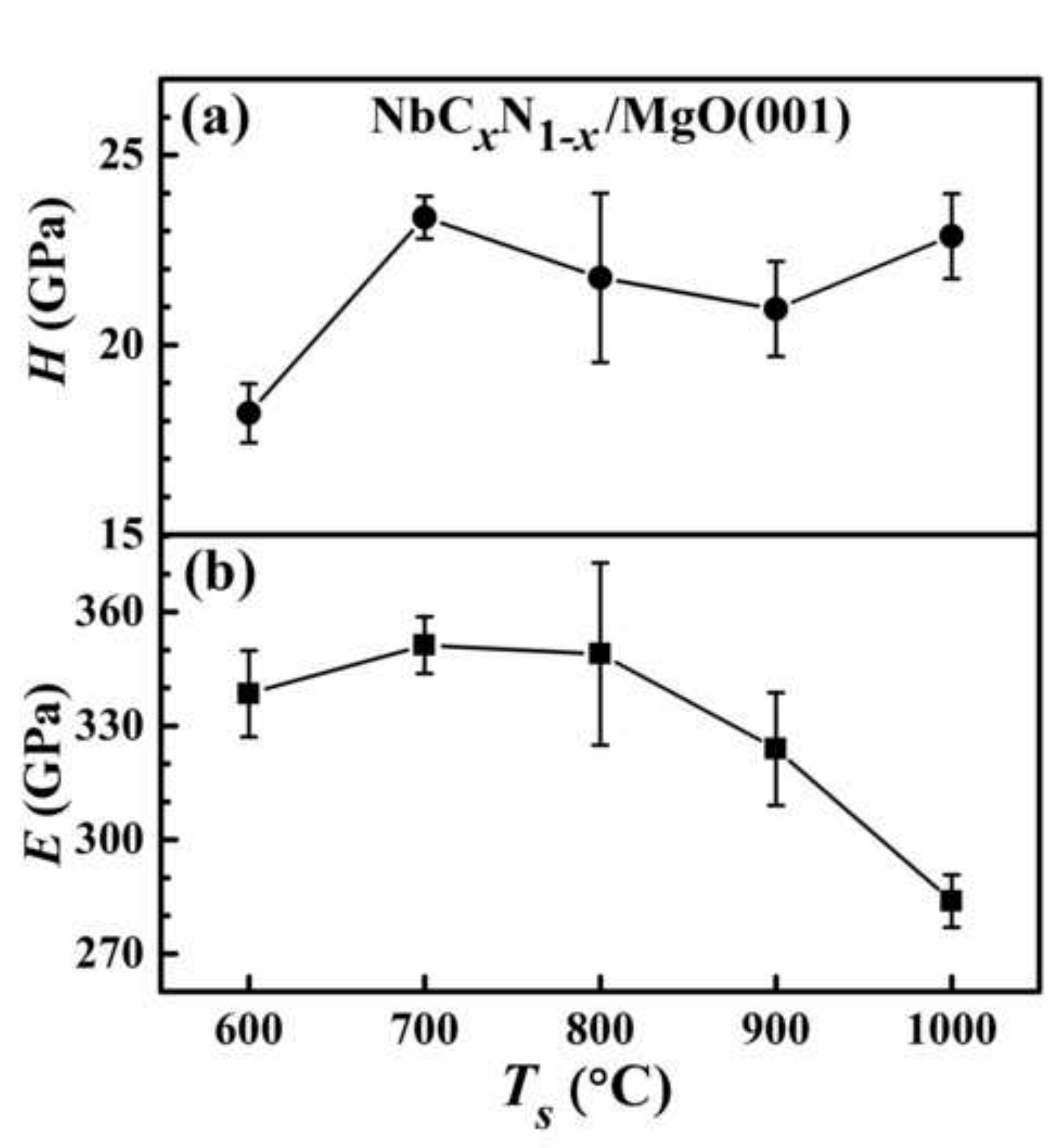

Figure 4 


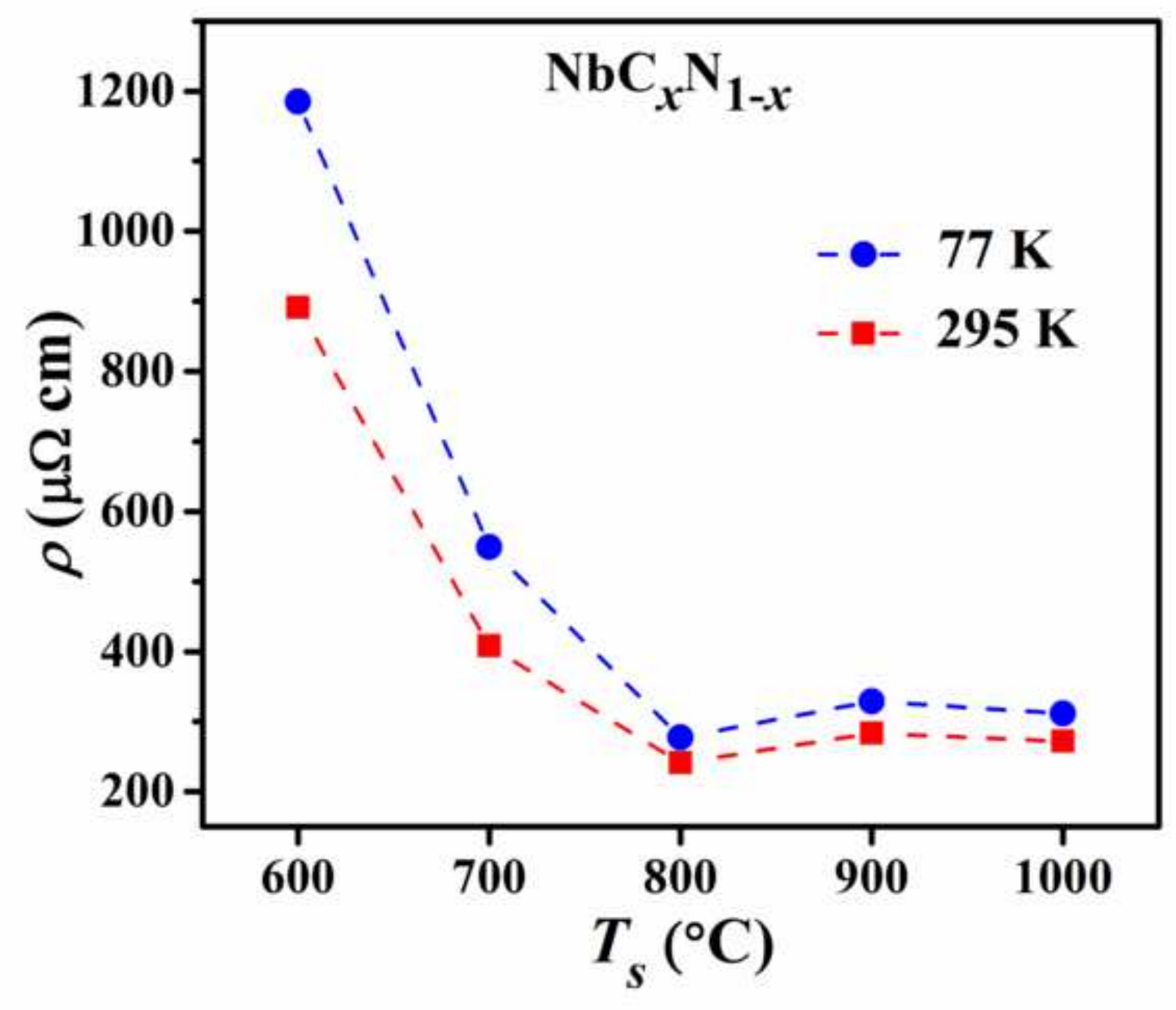

